\title{
Emphysematous cholecystitis. Advantages of abdominal ultrasound in the ED
}

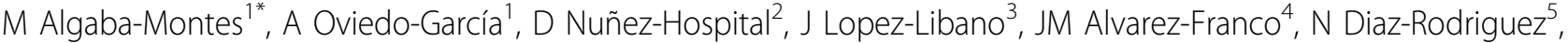 \\ A Rodriguez-Lorenzo ${ }^{6}$
}

From 9th WINFOCUS World Congress on Ultrasound in Emergency and Critical Care Hong Kong. 6-9 November 2013

\section{Background}

Emphysematous cholecystitis (EC) is an entity with high morbidity and mortality, and therefore require a diagnosis agile and dynamic, allowing appropriate management to avoid complications. The emergency ultrasound (US) allows a versatile and comprehensive management, improving the prognosis of this disease in the majority of cases.

\section{Objective}

we present a case of EC, diagnosed at ER, through the use of US scanning used by Emergency Phisicians.

\section{Patients and methods}

a patient with abdominal pain, with a final diagnosis of an EC assessing US, performed by EP.

\section{Results}

We report the case of a 72 year old patient with prior stroke without sequelae and hypertensive, with abdominal pain of 7 days duration, high fever and bilious vomiting. Physical examination was marked hypotension $(80 / 45 \mathrm{mmHg})$, distal coldness, pallor and sweating, $38.5^{\circ} \mathrm{C}, 145 \mathrm{spm}$. The distended abdomen with abolished peristalsis and positive Murphy right upper quadrant. Rest without findings of interest. Analytically glucose was $505 \mathrm{mg} / \mathrm{dl}$, creatinine of $2.44 \mathrm{mg} / \mathrm{dl}$, bilirubin $2.2 \mathrm{mg} / \mathrm{dl}$, AST 350, LDH 407, amylase 125, 19500 leukos with neutrophilia and $\mathrm{pH}$ of 7.13, with lactic 12. Was performed in consultation abdominal US showed a thickened gallbladder wall $(8 \mathrm{~mm})$, wellcircumscribed, oval, distended and gas in the same light, compatible with emphysematous cholecystitis. Support measures were initiated, antibiotics, insulin therapy and emergency surgery was indicated. This allowed a favorable high after joining UCI in 7 days without further complications.

\section{Conclusion}

EC is a rare entity that represents $1 \%$ of all cholecystitis, clinically indistinguishable, but with a worse prognosis (25\% mortality) and more complications. Here debut comes as poorly controlled diabetes. The use of abdominal US in ER allows for both a rapid and versatile, with proper treatment start, this being vital to good patient outcomes.

\section{Authors' details \\ ${ }^{1}$ Emergency Department, Valme Hospital, Seville, Members of the Working Group of Ultrasound SEMES_Andalucía and SEMERGEN, Spain. ${ }^{2}$ Emergency Department, Valme Hospital. Seville, Spain. ${ }^{3}$ Critical Care Department, Miramar Hospital, Mallorca, Member of the Working Group of Ultrasound SEMERGEN, Spain. ${ }^{4}$ Emergency Department, IB-Salut, Ibiza, Member of the Working Group of Ultrasound SEMERGEN, Spain. ${ }^{5}$ Primary Care. Barbadás Primary Care Center. Ourense, Member of the Working Group of Ultrasound SEMERGEN, Spain. ${ }^{6}$ Radiology Department. Perpetuo Socorro Hospital, Vigo, Member of the Working Group of Ultrasound SEMERGEN, Spain.}

Published: 31 January 2014

\section{Reference}

1. Fox JC, Solley $\mathrm{M}$, Anderson $\mathrm{CL}$, et al: Prospective evaluation of emergency physician performed bedside ultrasound to detect acute appendicitis. Eur J Emerg Med 2008, 15(2):80-5.

doi:10.1186/2036-7902-6-S1-A7

Cite this article as: Algaba-Montes et al:: Emphysematous cholecystitis. Advantages of abdominal ultrasound in the ED. Critical Ultrasound Journal 2014 6(Suppl 1):A7. 